\title{
To study the association of antiphospholipid syndrome in patients with bad obstetric history
}

\author{
Ajitha Ravindran R. K.*, Jayshree V. Vaman, Nirmala C., Sujatha T. L.
}

Department of Obstetrics and Gynaecology, Government Medical College, Trivandrum, Kerala, India

Received: 21 October 2016

Accepted: 07 November 2016

\section{*Correspondence:}

Dr. Ajitha Ravindran R. K.,

E-mail: ajitharoy7@gmail.com

Copyright: ( $)$ the author(s), publisher and licensee Medip Academy. This is an open-access article distributed under the terms of the Creative Commons Attribution Non-Commercial License, which permits unrestricted non-commercial use, distribution, and reproduction in any medium, provided the original work is properly cited.

\section{ABSTRACT}

Background: Antiphospholipid syndrome is an autoimmune condition characterized by vascular thrombosis and /or pregnancy morbidity in the presence of antiphospholipid antibodies. A failure or significant delay in recognizing APS as the underlying disease entity may leave to the loss of an opportunity to prevent serious consequences of the disease and the associated pregnancy complications. Aim of the study was to study the association of Antiphospholipid Syndrome (APS) in patients with bad obstetric history (BOH).

Methods: Patients registered in Obstetrics and Gynecology Department SAT Hospital, Medical College, Trivandrum, Kerala with bad obstetric history $(\mathrm{BOH})$ meeting the inclusion and exclusion criteria were recruited for the study. They were followed up in the postnatal ward after abortion and preterm delivery as per protocol for bad obstetrics outcome evaluation. They were offered lab test in standard labs for APL Syndrome especially LAC and anticardiolipin antibodies IgM and IgG. Those tested positive were retested 12 weeks later also to confirm the test. Then the various adverse pregnancy outcomes were studied in both APLA positive and negative groups.

Results: The association of APLA with bad obstetric history (BOH) in the present study are as follows- Late miscarriages- $16 \%$, miscarriages less than 10 weeks- $12 \%$, Preterm- $10.8 \%$, unexplained death-14\%, Severe Preeclampsia-12.3\%, IUGR-11.8\%, Abruption-11.1\% of which late miscarriages more than 10 weeks was the commonest association.

Conclusions: The study shows that women with bad obstetric history $(\mathrm{BOH})$ and those cases where miscarriage occurred after the appearance of foetal cardiac activity should be investigated for APLA in the preconceptional period itself in the next pregnancy earlier and if positive should be given prophylaxis for the same to prevent a miscarriage in future pregnancy.

Keywords: Antiphospholipid syndrome, Autoantibody, Bad obstetric history

\section{INTRODUCTION}

Of the many factors distributed as causes of recurrent pregnancy losses, Antiphospholipid syndrome (APS) is a problem which if treated can lead to successful pregnancy outcomes in $80 \%$ of cases. ${ }^{1}$ Antiphospholipid syndrome (APS) is defined as an acquired autoimmune thrombotic disorder in which patients present with vascular thrombosis or recurrent pregnancy losses along with lab evidence for antibodies against phospholipids or phospholipid binding protein cofactors in their blood such as lupus anticoagulant, anticardiolipin and antibeta2 glycoprotein-I. ${ }^{2}$

Approximately one in ten pregnancies end in early death of the fetus before 20 weeks of gestation and one in two hundred pregnancies end in late fetal loss. When fetal losses occur in second and third trimester it may due to excessive thrombosis of placental vessels or placental infraction due to APS if other congenital, chromosomal, anatomic and hormonal causes could be excluded. ${ }^{3}$ The rate of recurrence of any of these pregnancy outcomes 
such as recurrent miscarriages, fetal death, severe preeclampsia, IUGR and abruption in subsequent pregnancies are as high as $46 \%$. So they should be screened for thrombophilias and women should receive prophylaxis with low dose aspirin and subcutaneous heparin once fetal cardiac activity is documented. ${ }^{4}$

Tulpalla M et al in 1996 states that APLA are directed against platelets and vascular endothelium predisposing to thrombosis. ${ }^{5}$ Rand et al states that APLA have been linked to reduced levels of antithrombotic phospholipid binding proteins on the surface of trophoblast and endothelial cells (annexin v). These abnormalities may result in thrombosis during the development of the normal maternoplacental circulation, perhaps through interference with trophoblastic annexin $\mathrm{V}$, which is abundant in the human placenta, or by impairing trophoblastic hormone production or invasion. ${ }^{6}$ ALPA seem to cause direct dysfunction of the trophoblast as well as activation of compliment at fetomaternal interface, resulting in an impaired exchange of blood components between mother and fetus which can lead to early miscarriage, pre-eclampsia, IUGR or even Intrauterine death. ${ }^{7}$ Indeed obstetric histories detailed in some case series of women with APS suggest that $40 \%$ or more of pregnancy losses reported by women with LA or medium to-high positive IgM anticardiolipin antibodies occurred during the fetal period $\geq 10$ menstrual weeks of gestation. In women with recurrent pre-embryonic and embryonic pregnancy loss $<10$ weeks gestation without significant past medical history has shown that $10 \%$ to $20 \%$ of these women have detectable antiphospholipid antibodies. More recently APS-related pregnancy loss has been extended to include women with early recurrent pregnancy loss including those occurring in the preembryonic (<6 menstrual weeks of gestation) and embryonic periods (6 through 9 menstrual weeks of gestation). ${ }^{8}$

The presence of more than one type of aPL (both LA and aCLs) greatly increases the woman's risk of pregnancy induced hypertension and predisposes her to more severe preeclampsia. ${ }^{9}$ Even with currently used treatment protocols the rate of IUGR approaches $30 \%$. Rate of preterm birth ranges from $32-65 \% .{ }^{10}$ A smaller study by Polzin et al demonstrated that positive aCL was associated with FGR. However, LA was not detected in any of women with this cohort. IUD and still birth have been reported to occur in women with APS as a result of placental abruption. $^{11}$

\section{METHODS}

Design of study was a descriptive cross sectional study.

Duration of the study was one year.

\section{Study population}

The patients who registered in Obstetrics and Gynaecology department, SAT Hospital, Medical College, Thiruvananthapuram with adverse pregnancy outcomes are recruited for the study.

\section{Inclusion criteria}

Patients with 2 or more first trimester miscarriages, patients with one or more second trimester miscarriages and those with pregnancy losses less than 34 weeks due to severe Pre-eclampsia, IUGR, abruption and unexplained intra uterine death.

\section{Exclusion criteria}

Congenital malformations of foetuses excluded by gross morphological appearance, USG examination or histopathology. Hormonal causes like diabetes, thyroid diseases, anatomical causes and cervical incompetence in the mother are excluded by USG.

Those who fulfil the selection criteria are recruited for the study. They are followed up in the postnatal ward after abortion or preterm delivery. Patients in the study group were divided according to the pregnancy morbidity i.e.; those with miscarriages less than 10 weeks, miscarriages 10 to 25 weeks and those with adverse pregnancy outcomes less than 34 weeks which include preterm births and unexplained IUD. Only those patients under 34 week's gestation were included in the study. Detailed information regarding socio-demographic factors, previous pregnancy losses-their gestational age, documentation of fetal heart, any congenital anomalies, complications during antenatal period like severe Preeclampsia, IUGR and abruption remote from term, weight of foetuses and investigation results were collected.

After informed consent, data are collected by a prestructured interview schedule combined with hospital documents and available lab tests. These patients were subjected as per the protocol for bad obstetric outcome evaluation. The patients in our study group were offered laboratory tests in standard labs with expert quality assurance services for APLA syndrome especially lupus anticoagulant assay and anti- cardiolipin IgM and IgM. Those who were tested positive were retested 12 weeks later also to confirm the test. They were done in the same laboratory to help in standardization of results.

The sample size proposed for the study is calculated from the formula $\mathrm{n}=\left(\mathrm{Zx}^{2} \times \mathrm{p} \times \mathrm{q}\right) / \mathrm{d}^{2}$ where $\mathrm{Z} \times=1.96, \mathrm{p}=$ prevalence form the pilot study $=10, q=(100-p)=90$. When $d$ (margin of sampling error) is taken as 4 , the sample size was calculated to be 216. Data regarding various study variables are collected from all these patients by a pre-structured interview schedule and 
analysed using statistical package Excel/SPSS. The significance of findings was tested and data interpreted.

\section{RESULTS}

Table 1: Distribution according to pregnancy morbidity.

\begin{tabular}{|llllll|}
\hline \multirow{2}{*}{$\begin{array}{l}\text { Pregnancy } \\
\text { morbidity }\end{array}$} & \multicolumn{2}{l}{ APLA } & \multicolumn{2}{l|}{ Positive } & \multicolumn{2}{l|}{ Negative } & Total \\
& No & $\mathbf{\%}$ & No & \% & \\
\hline Abortions $<10$ weeks & 14 & 12 & 103 & 88.0 & 117 \\
\hline Abortions $10-24$ & 13 & 16 & 68 & 84 & 81 \\
\hline IUD & 10 & 14.1 & 61 & 85.9 & 71 \\
\hline PTB & 17 & 10.8 & 141 & 89.2 & 158 \\
\hline
\end{tabular}

In the study group 117 patients had history of abortions less than 10 weeks, 81 patients had history of late miscarriages more than 10 weeks, 71 patients had IUD and 158 patients had pre term births of which $12 \%$ was APLA+in abortions $<10$ wks, $16 \%$ was APLA+in abortions 10-24 wks, 14\% was APLA+in IUD s and $10.8 \%$ APLA+in preterm births.

Table 2: Distribution of patients according to whether early or late miscarriages.

\begin{tabular}{|llllll|}
\hline \multirow{2}{*}{ A bortions } & \multicolumn{2}{l}{ APLA } & \multicolumn{3}{l|}{ Total } \\
\cline { 2 - 6 } & Positive & \multicolumn{2}{l|}{ Negative } & \\
\cline { 2 - 6 } & No & $\%$ & No & \% & \\
\hline Less than 10 weeks & 14 & 12.0 & 103 & 88.0 & 117 \\
\hline $10-24$ weeks & 13 & 16.0 & 68 & 84.0 & 81 \\
\hline
\end{tabular}

Among subjects with abortions in less than 10 weeks gestations $12 \%$ were APLA positive cases and in 10-24 weeks gestation the corresponding percentage was $16 \%$.

Table 3: Association of APLA with BOH.

\begin{tabular}{|llllll|}
\hline \multirow{2}{*}{ Complications } & \multicolumn{2}{l}{ APLA } & \multicolumn{2}{l|}{ Total } \\
\cline { 2 - 6 } & \multicolumn{2}{l}{ Positive } & \multicolumn{2}{l|}{ Negative } & \\
\cline { 2 - 6 } & No & \% & No & \% & No \\
\hline Severe PE & 10 & 12.3 & 71 & 87.6 & 81 \\
\hline FGR & 9 & 11.8 & 67 & 88.2 & 76 \\
\hline Abruption & 4 & 11.1 & 32 & 88.9 & 36 \\
\hline Unexplained IUD & 10 & 14.1 & 61 & 85.9 & 71 \\
\hline
\end{tabular}

- Severe PE - $12.3 \%$

- FGR - $11.8 \%$

- Abruption - $11.1 \%$

- Unexplained IUD - $14.1 \%$

\section{DISCUSSION}

In the present study of 216 cases with bad obstetric history $(\mathrm{BOH}), 27$ causes were found to be APLA positive giving a prevalence of $12.5 \%$. The $95 \%$ confidence limits are $8.4 \%$ to $17.6 \%$.

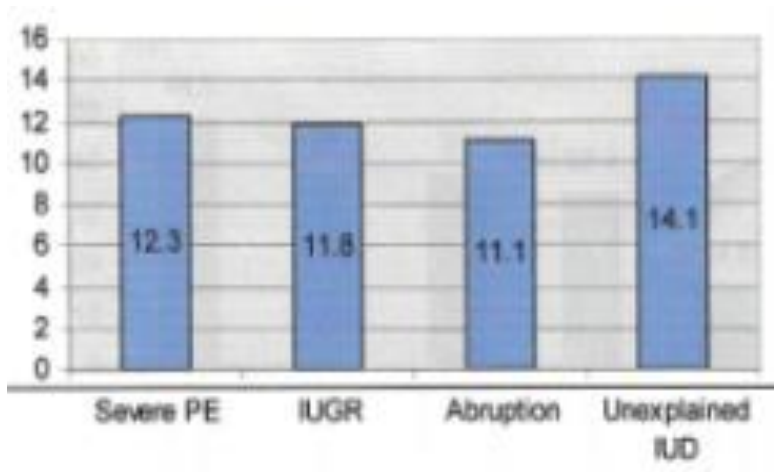

Figure 1: Association of APLA with various adverse pregnancy outcomes.

Many of the adverse pregnancy outcomes described (early onset preeclampsia, FGR placental abruption, still births) are the end result of abnormal placentation and this supports the concept that placental failure is the mechanism by which APLA are associated with late losses.

The association of APLA with bad obstetric history $(\mathrm{BOH})$ in the present study are as follows-late miscarriages- $16 \%$, miscarriages less than 10 weeks-12\%, preterm-10.8\%, unexplained death-14\%, severe preeclampsia-12.3\%, FGR-11.8\%, abruption-11.1\% of which late miscarriages more than 10 weeks was the commonest association.

The prevalence of APS in women with recurrent miscarriage is $15 \%$ compared to $2 \%$ in women with normal obstetric histories an Rai et al 1995. ${ }^{4,12}$ 9Branch and Co-workers found a $16 \%$ incidence of antiphospholipid antibody in 43 women with severe preeclampsia before 34 weeks. Similarly Moodley and associates found antiphospholipid antibodies in $11 \%$ of 34 women with severe pre-eclampsia before 30 weeks. $^{13}$ Polzin 11 and Colleagues 1991 identified antiphospholipid antibody in one fourth of 37 women with growth restricted foetuses.

Approximately one third of women with APS will develop preeclampsia during pregnancy. ${ }^{14}$ In different studies conducted by Utah, St. Thomas and St. Marys et al the rates of severe PE was $27 \%, 18 \%$ and $11 \%$ respectively and that of IUGR are $31 \%, 31 \%$ and $15 \%$ respectively. ${ }^{15,16}$

To find whether there is any risk factor associated with APLA, contraceptive history was enquired in detail. But majority did not use any contraception and few used barrier contraception. No patient in the APLA group used OC pills in the present study. Association with OC pills could not be studied as no patient in APLA group used OC pills. There were 7 cases of hypothyroidism of which 
none were in APLA positive group. There were 3 cases of SLE of which none were APLA positive. Thus no association was found with autoimmune diseases like hypothyroidism, S LE, and APS in the present study.

\section{CONCLUSION}

Out of various adverse pregnancy outcomes noted in the study, the associations with APLA were $12 \%$ in abortions less than 10 weeks, $16 \%$ in abortions between 10-24 weeks, $14.1 \%$ with unexplained IUD, $12.3 \%$ with severe Pre-eclampsia, $11.8 \%$ IUGR and $11.1 \%$ with abruption. It shows that women with bad obstetric history $(\mathrm{BOH})$ should be investigated for APLA earlier and if positive, preconception counselling given and treatment started earlier.

In APLA positive cases with recurrent miscarriages majority of fetal loses occurred after the appearance of cardiac activity. Hence APLA should be looked for particularly in those cases where miscarriages occur after the appearance of fetal cardiac activity.

We have to differentiate women with recurrent early pregnancy losses less than 10 weeks from women who have had late pregnancy losses, preterm delivery less than 34 weeks, severe early onset pre-eclampsia HELLP syndrome and thus obstetric APS need to be further defined. The various anticoagulant regimes and the optimum duration of thromboprophylaxis in obstetric APS should be standardized. There were 4 cases of vascular thrombosis and LAC was found to be positive in all showing the association of LAC with thrombosis.

\section{Funding: No funding sources}

Conflict of interest: None declared

Ethical approval: The study was approved by the Institutional Ethics Committee

\section{REFERENCES}

1. Wilson WA, Gharavi AE, Koike T, Lockshin MD, Branch DW, Piette JC, et al. International consensus statement on preliminary classification criteria for definite antiphospholipid syndrome: Report of an International workshop. Arthritis and Rheumatism. 1999;42:1309-11.

2. Blume JE, Miller CC. Antiphospholipid syndrome: a review and update for the dermatologist. Cutis. 2006;78:409-15.

3. Clifford K, Rai R, Regan L. Future pregnancy outcome in unexplained recurrent first trimester miscarriage. Hum Reprod. 1997;12:387-9.

4. Pattison NS, Chamley LW, Birdsall M. Does aspirin have a role in improving pregnancy outcome for women with the antiphospholipid syndrome? A randomized controlled trial. Am J Obster Gynecol. 2000;183:1008.
5. Destefano K, Belogolovkin V, Salihu H. Does anti beta 2 glycoprotein I improve the detection rate of antiphospholipid syndrome in pregnancy? Abstract no. 521. Presented at the 29th Annual Meeting of the Society for Maternal- Fetal Medicine. 2009;26-31.

6. Bowie EJW, Thompson JH, Pascuzzi CA. Thrombosis in systemic Iupus erythramatosus despite circulating anticoagulants. J Lab Clin Med. 1963;62:416-30.

7. Branch DW, Khamashta MA. Antiphospholipid syndrome: obstetric diagnosis, management, and controversies. Obstet Gynecol. 233;101:133-44.

8. Yetman DL, Kutteh WH. Antiphospholipid antibody panels and recurrent pregnancy loss: prevalence of anticardiolipin antibodies compared with other antiphospholipid antibodies. Fertile Steril. 1996;66:540-54.

9. Branch DW, Silver R, Pierangeli S. Antiphospholipid antibodies other than lupus anticoagulant and anticardiolipin antibodies in women with recurrent pregnancy loss, fertile controls, and antiphospholipid syndrome. Obstret Gynecol. 1997;89:549.

10. Moodley J. Ramphal SR, Duursma J. antiphospholipid antibodies in eclampsia. Hypertens Preg. 1995;14:179.

11. Lockshin MD, Sammaritano LR, Schwartzman S. Validation of the Sapporo criteria for antiphospholipid syndrome. Arthritis Rheum. 2000;43:440-3.

12. Polzin WJ, Kopelman JN, Robinson RD. The association of antiphospholipid antibodies with pregnancies complicated by fetal growth restriction. Obster Gynecol. 1991;78:1108.

13. Rai R, Cohen H, Dave M, Regan L. Randomized controlled trial of aspirin plus heparin in pregnant women with recurrent miscarriage associated with phospholipid antibodies (or antiphospholipid antibodies), BMJ. 1997;314:253.

14. Clark EAS, Silver RM, Branch DW. Do antiphospholipid antibodies cause preeclampsia and HELLP syndrome? Curr Rheum Reports. 2007;9:219.

15. Lima F. Khamashta MA, Buchanan NMM, Kerslake S. Hunt BJ. Hughes GRV. A study of sixty pregnancies in patients with the antiphospholipid syndrome. Clin Exp Reheumatol. 1996;14:131-6.

16. Backos M, Rai R, Baxter N, Chilcott IT, Cohen H, Regan L. Pregnancy complications in women with recurrent miscarriage associated with antiphospholipid antibodies treated with low dose aspirin and heparin. $\mathrm{Br} \mathrm{J}$ Obstet Gynaecol. 1999;106(2):102-7.

Cite this article as: Ajitha RRK, Jayshree VV, Nirmala C, Sujatha TL. To study the association of antiphospholipid syndrome in patients with bad obstetric history. Int J Reprod Contracept Obstet Gynecol 2016;5:4156-9. 